\title{
Synthesis and Field Emission Properties of Carbon Nanowire-Single Walled Carbon Nanotube Networks Hybrid Films
}

\author{
Lijun Wang*, Linghong Liu, Xiaoping Wang*, Ying Yu, Junwei Wen, Jian Li \\ College of Science, University of Shanghai for Science and Technology, Shanghai 200093, China \\ Email: ${ }^{*}$ wlipjchina@163.com, ${ }^{*}$ wxpchina64@aliyun.com
}

Received 18 August 2015; accepted 15 October 2015; published 22 October 2015

\begin{abstract}
Carbon nanowire (CNW)-singlewalled carbon nanotube (SWCNT) networks hybrid films with a large area $\left(\sim 400 \mathrm{~mm}^{2}\right)$ are grown on molybdenum (Mo) layers by microwave plasma chemical vapour deposition system. The Mo layers, which were deposited on $\mathrm{Al}_{2} \mathrm{O}_{3}$ ceramic substrates through electron beam evaporation deposition, were pretreated by a laser-grooving (LG) technology. Furthermore, the surface morphology, micro-structure and field emission properties of these samples are characterized by scanning electron microscope, Raman spectra, and field emission I - V measurements. A CNW-SWCNT networks hybrid film was formed in the surface of Mo layer, but the laser etched area (linear pits array area) the distribution of the CNW-SWCNT networks density is lower than the un-etched area CNW-SWCNT networks distribution density. The diameter of the CNWs and SWCNTs, respectively in the $8-15 \mathrm{~nm}$ and $0.9-1.5 \mathrm{~nm}$ range, and the length of CNW-SWCNTs ranges from $1 \mu \mathrm{m}$ to $4 \mu \mathrm{m}$. The growth mechanisms of the films were discussed. Effects of LG pretreatment on surface morphologies and microstructure of the hybrid films were investigated. The field electron emission experimental results shown that the ture on field as low as $1.6 \mathrm{~V} / \mu \mathrm{m}$, and a current density of $0.15 \mathrm{~mA} / \mathrm{cm}^{2}$ at an electric field of $4.3 \mathrm{~V} / \mu \mathrm{m}$ was obtained.
\end{abstract}

\section{Keywords}

Carbon Nanowire, Singlewalled Carbon Nanotube, Chemical Vapour Deposition, Field Emission

\section{Introduction}

Since carbon nanotubes (CNTs) were discovered [1], various nano-carbon field electron emission (FE) materials have been extensively studied in recent years for their potential applications such as flat panel displays, high temperature microelectronics and intense electron sources for microwave generation [2]-[10]. But until now, the macroscopic properties of carbon-based film emitter have not yet been completely achieving the level of practical application, therefore, research how to synthesis with all kinds of complicated morphology carbon film and

\footnotetext{
${ }^{*}$ Corresponding authors.
}

How to cite this paper: Wang, L.J., Liu, L.H., Wang, X.P., Yu, Y., Wen, J.W. and Li, J. (2015) Synthesis and Field Emission Properties of Carbon Nanowire-Single Walled Carbon Nanotube Networks Hybrid Films. World Journal of Engineering and Technology, 3, 97-104. http://dx.doi.org/10.4236/wjet.2015.33C015 
further research carbon film field emission performance is necessary. The nanowire is a new nanostructure, with the diameter of the order of a nanometer $\left(10^{-9}\right.$ meters). Recently, nanowires have attracted much attention due to their novel wire structure, unique electrical, optical properties and the potential applications in the fields of optoelectronics [11]-[17] and field emitters [18]-[22]. Carbon nanowire (CNW) as a new type of carbon nanomaterials has aroused the attention of some scholars, and it has been investigated in the synthetic technology and material properties by some researchers [23]-[27]. Moreover, the possibility of synthesizing both SWCNTs and CNWs in the same process has been rarely reported [28] [29].

In this paper, we report the fabrication of a series of larger areas $\left(400 \mathrm{~mm}^{2}\right) \mathrm{CNW}$-single walled CNT (SWCNT) networks hybrid films on Mo coated $\mathrm{Al}_{2} \mathrm{O}_{3}$ ceramic substrate by using microwave plasma-assisted chemical vapor deposition (MPCVD) technique, and the Mo coated layers was pretreated by a laser-grooving (LG) technique. The surface morphologies and microstructure of the as-deposited CNW-SWCNT networks hybrid films were characterized. It was found that the laser etched area (linear pits array area) the distribution of the CNW-SWCNT networks density is lower than the un-etched area CNW-SWCNT networks distribution density. The CNWs is between 8-15nm in diameter and the diameter of the SWCNTs is about between $0.9-1.5 \mathrm{~nm}$, and CNW-SWCNT length is between $1-4 \mu \mathrm{m}$. FE properties of CNW-SWCNT networks hybrid films were further investigated, and a current density $\sim 0.15 \mathrm{~mA} / \mathrm{cm}^{2}$ at an electric field of $4.3 \mathrm{~V} / \mu \mathrm{m}$ and a threshold electric field of $<1.6 \mathrm{~V} / \mu \mathrm{m}$ are obtained.

\section{Experimental}

In order to gain a rough surface morphology, the $\mathrm{Al}_{2} \mathrm{O}_{3}$ ceramic substrates were first polished by Muller, and then they were cleaned in an ultrasonic cleaning machine for $30 \mathrm{~min}$. After that, electron beam deposition system was used solely for Mo deposition on ceramic substrates with high purity (99.99\%) metal Mo as deposition target. The thickness of Mo coated layer is $2000 \mathrm{~nm}$ controlled by films thickness monitor. Furthermore, Mo films were pretreated by LG technology. The groove width is $50 \mu \mathrm{m}$, which was designed by drawing software system. The sputtering current and frequency were given to control the groove depth. The specific parameters used for the LG process are listed in Table 1.

Subsequently we prepared CNW-SWCNT networks hybrid films on these pretreated substrates by MPCVD process under the reaction conditions. The typical parameters used for the CVD process are shown in Table 2.

The surface morphology and microstructure of CNW-SWCNT networks hybrid films deposited on Mo layers were characterized by Raman spectrum, energy dispersive spectroscopy (EDS) and field emission scanning electron microscopy (FE-SEM). And the field emission properties of CNW-SWCNT hybrid films were tested by the parallel-plate diode structure in an ultra vacuum chamber evacuated to a pressure of $4 \times 10^{-4} \mathrm{~Pa}$ with a

Table 1. Parameters employed for the LG process.

\begin{tabular}{cc}
\hline LG process parameters & Values \\
\hline Sputtering current $(\mathrm{A})$ & 5.0 \\
Impulse frequency $(\mathrm{Hz})$ & 1000 \\
Laser wavelength $(\mu \mathrm{m})$ & 10.64 \\
Groove depth $(\mu \mathrm{m})$ & 0.05 \\
Groove width $(\mu \mathrm{m})$ & 50 \\
Line density $($ line $/ \mathrm{mm})$ & 7 \\
\hline
\end{tabular}

Table 2. Parameters employed for the MPCVD process.

\begin{tabular}{cc}
\hline CVD process parameters & Values \\
\hline Methane/hydrogen gas flows (sccm) & $16 / 85$ \\
Substrate temperature $\left({ }^{\circ} \mathrm{C}\right)$ & 600 \\
Total gas pressure (KPa) & 6.5 \\
Deposition time (min) & 60 \\
Microwave power (W) & 1300 \\
\hline
\end{tabular}


turbo-molecular pump. CNW-SWCNT hybrid film and phosphor-coated ZnO:Al/glass were used as a cathode and an anode respectively, which were parallel separated by the mica spacer with a thickness of $100 \mu \mathrm{m}$. The current-voltage (I-V) characteristics were recorded by using a high voltage power supply and a digital ammeter. The current density-electric field (J-E) curves and the Fowler-Nordheim (FN) plots were obtained from the recorded I-V data. Field emission images were recorded with a CCD camera to know the distribution of the emitting sites.

\section{Results and Discussion}

Figure 1 shows Raman spectrums of the CNW-SWCNT networks hybrid networks film deposited on Mo layer. For the CNW-SWCNT networks hybrid film sample, the peak position of the D-band is around $1316 \mathrm{~cm}^{-1}$, which is assigned as $A_{1 g} D$ mode, associated with vibrations at defects such as vacancies, grain boundaries, substitution hetero-atoms and impurities [30] [31]. And the peak position of the G band is $1583 \mathrm{~cm}^{-1}$. It confirms that the film contained a significant amount of nano-crystalline graphite phase [32] [33]. The minor peak at 264 $\mathrm{cm}^{-1}$ and $168 \mathrm{~cm}^{-1}$ is the radial breathing mode (RBM) band, which appears only in the SWCNTs, explained by existed SWCNTs in the films. In addition, the 2D peak at $2593 \mathrm{~cm}^{-1}$ is the two-phonon overtone of the D band.

As given by $\omega=248 / \mathrm{d}$ (where $\omega$ is the Raman shift in $\mathrm{cm}^{-1}$ and $d$ is the diameter of SWCNTs in $\mathrm{nm}$ ), and depending on the position of RBM, the diameter distribution of the present nanotubes was estimated to be of 0.9 $-1.5 \mathrm{~nm}$ [28] [34] [35].

Figure 2 showed FE-SEM images of a CNW-SWCNT hybrid film prepared on the Mo layer taken with different amplifications. Figure 2(b) and Figure 2(c) showed typical FE-SEM images taken from the laser etching area and the un-etching area, respectively. Surface morphology of the sample clearly shows the free growth of nano tubular or nano filamentous networks covered in all of the substrate surface. Because SWCNTs mainly includes $\mathrm{sp}^{2}$-bonded carbon atoms structure, whereas CNWs is composed of a mixture structure of $\mathrm{sp}^{2}$ and $\mathrm{sp}^{3}$ carbon bondings, the SEM and Raman test results fully prove that CNW-SWCNT networks hybrid film was synthesized.

The diameter of the CNWs was typically about $8-15 \mathrm{~nm}$, and the length of CNWs or SWCNTs range from 1 $\mu \mathrm{m}$ to $4 \mu \mathrm{m}$. But the laser etched area (linear pits array area) the distribution of the CNWs-SWCNTs hybrid networks density is lower than that of the un-etched area, as shown in Figure 2(d) and Figure 2(e).

The growth of carbon film was affected by pretreatments, because the LG pretreatment can destroyed accidented surface topography and formed the line pits array, as showed in Figure 2(a). During the MPCVD deposition process, plasma energy distribution would changed induced by linear pits array formed, thus affect the growth of carbon films. In addition, in the LG process, the portion of chiseled Mo particles was splashed into tiny fragments (powders), and eventually sprinkled on the surface of the remainder area, on which the fluffy structure of tiny Mo powder was formed. All of these tiny powders played the role as catalysts during carbon film formation process. So CNW-SWCNT networks structure was formed owing to action of tiny Mo powder catalysts. In short, fluffy Mo powder works to promote the formation of the CNW-SWCNT networks hybrid

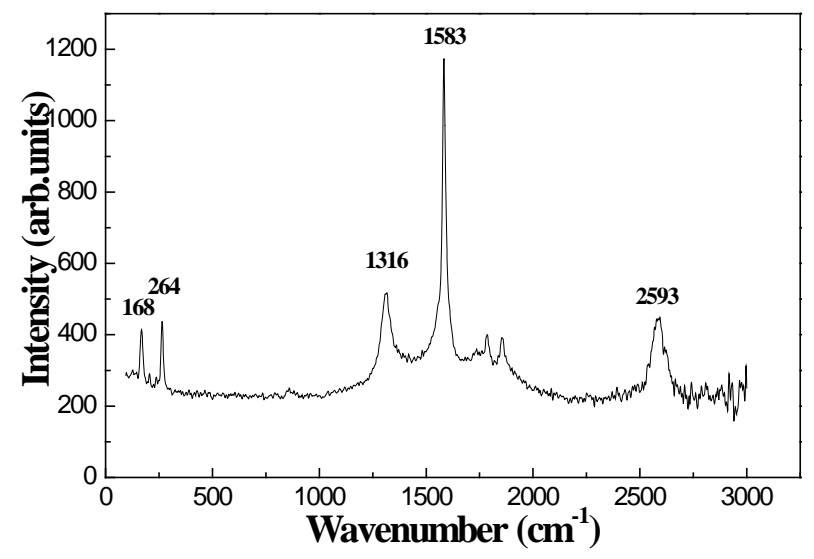

Figure 1. Raman spectra of CNW-SWCNT networks hybrid film deposited on Mo layer. 

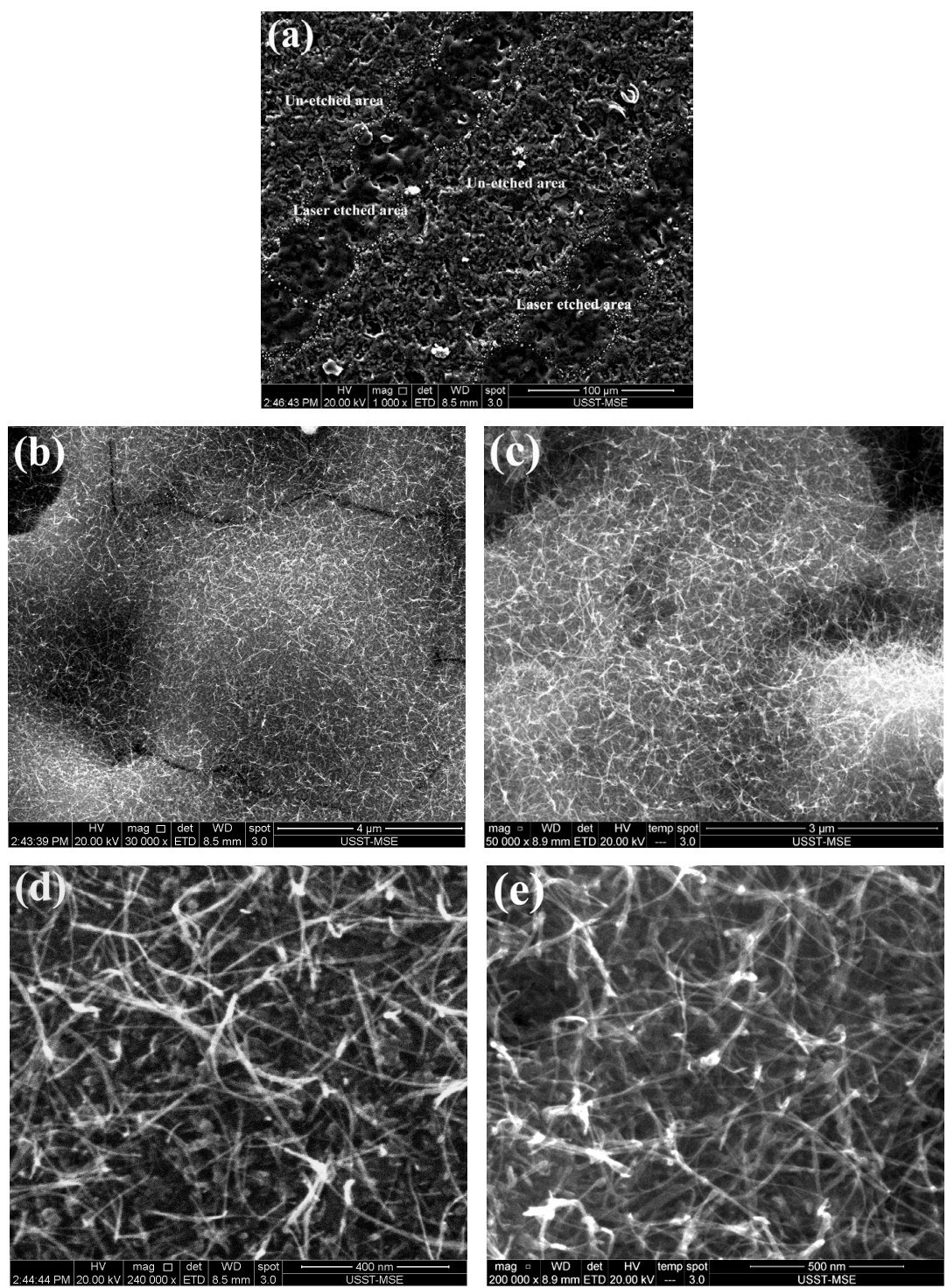

Figure 2. FE-SEM images of the CNW-SWCNT networks hybrid films deposited on Mo layer (a) laser etched area and the un-etched area of the overall appearance; (b) the laser etched area; (c) the unetched area; (d) and (e) are enlarged views of (b) and (c); respectively.

film. Relative to the unetched area, the laser etched area has a small number of tiny Mo powders, this result in the CNW-SWCNT network density exists in the laser etched area is lower than that exists in the un-etched area.

FE characteristics of the CNW-SWCNT networks hybrid films with an area of $400 \mathrm{~mm}^{2}$ were measured. In this study, the threshold $\mathrm{E}\left(\mathrm{E}_{\mathrm{th}}\right)$ was defined as $\mathrm{E}$ at which $\mathrm{J}=10 \mu \mathrm{A} / \mathrm{cm}^{2}$. For CNW-SWCNT networks hybrid film samples, $E_{\text {th }}=1.6 \mathrm{~V} / \mu \mathrm{m}$, and a current density of $0.15 \mathrm{~mA} / \mathrm{cm}^{2}$ was obtained at an electric field of 4.3 $\mathrm{V} / \mu \mathrm{m}$. Figure 3(a) and Figure 3(b) show, respectively, the J-E curves and F-N plots of CNW-SWCNT networks hybrid film deposited on Mo layer. In low electric field $(\mathrm{E}<3.5 \mathrm{~V} / \mu \mathrm{m})$, F-N plot is negative slope straight line corresponding to the classical electron tunneling mechanism. Different from the traditional F-N curve, the F-N plots of CNW-SWCNT hybrid films have not a negative slope linear relationship in high electric field (E > $3.5 \mathrm{~V} / \mu \mathrm{m})$. The reason may be in high field electronic transport rate has reached saturation, which makes electrons essentially transition in an instant and conduction band doesn't have enough electronic supplement, resulting the current is no significant increase.

Figure 4(a) and Figure 4(b) shows the FE images recorded by a CCD camera at macroscopic electric field E $=3.1 \mathrm{~V} / \mu \mathrm{m}$ and $4.3 \mathrm{~V} / \mu \mathrm{m}$. The area of the biggest image is about $400 \mathrm{~mm}^{2}$. It is shown that for the samples, at 

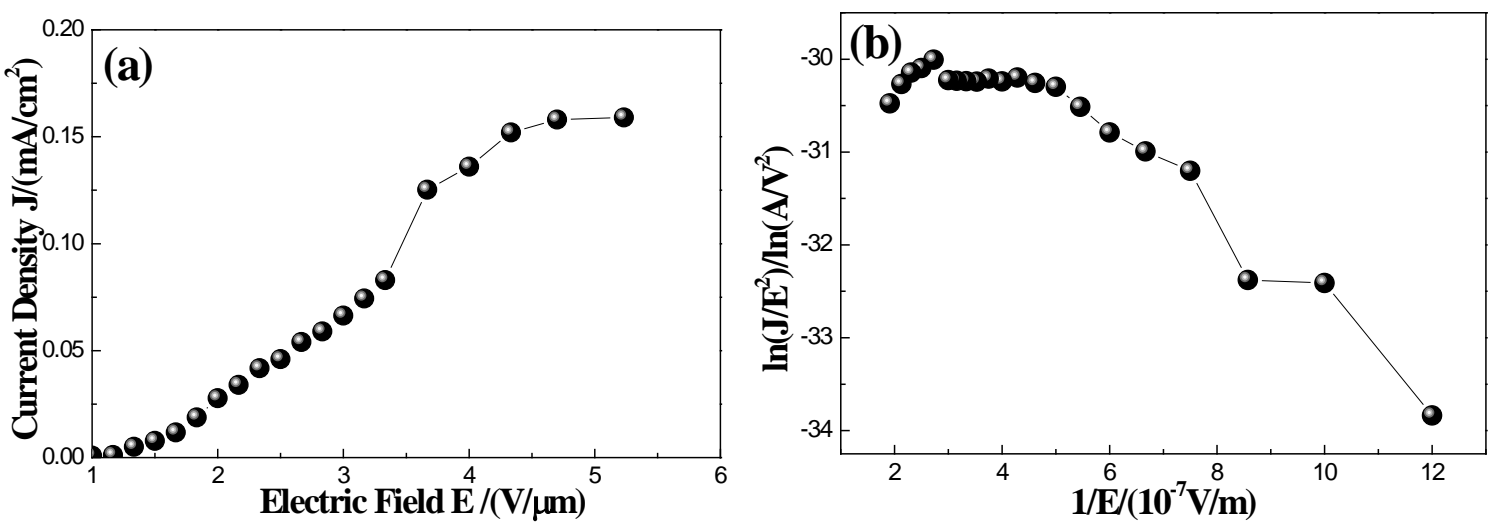

Figure 3. J-E curves and F-N plots of CNW-SWCNT hybrid film.
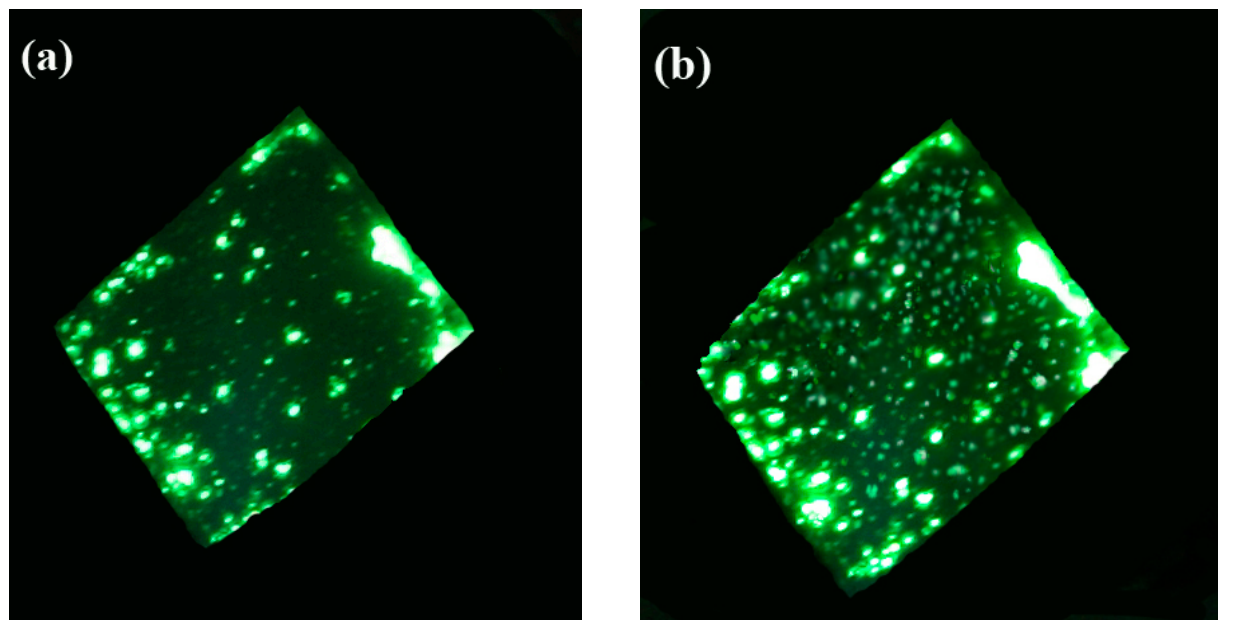

Figure 4. Image of FE site distribution obtained for CNW-SWCNT networks hybrid films cathode with the macroscopic field $\mathrm{E}=3.1 \mathrm{~V} / \mu \mathrm{m}(\mathrm{a})$ and $\mathrm{E}=4.3 \mathrm{~V} / \mu \mathrm{m}(\mathrm{b})$.

$3.1 \mathrm{~V} / \mu \mathrm{m}$, dozens of emission spots were observed, at $4.3 \mathrm{~V} / \mu \mathrm{m}$ the emission spots almost distribute the entire specimen surface, but the FE uniformity is not ideal.

\section{Conclusion}

CNW-SWCNT networks hybrid films were successfully fabricated on Mo coated $\mathrm{Al}_{2} \mathrm{O}_{3}$ ceramic substrates utilizing MPCVD technique (the Mo films substrates were pretreated by the LG technology). CNW-SWCNT networks hybrid films are formed in all of the substrate surface. Growth of carbon films was influenced by unusual microstructure of the substrate and therefore causes different plasma energy distribution. The CNW-SWCNT networks hybrid structure formed is ascribed to fluffy structure of tiny Mo powder splashed in LG pretreatment acted as catalysts. FE characteristics of the CNW-SWCNT networks hybrid films were measured, and the FE current density was $0.15 \mathrm{~mA} / \mathrm{cm}^{2}$ at an electric field of $4.3 \mathrm{~V} / \mu \mathrm{m}$ and the area of the biggest image is about 400 $\mathrm{mm}^{2}$.

\section{Conflict of Interests}

The authors declare that there is no conflict of interests regarding the publication of this paper.

\section{Acknowledgments}

This work is financially supported by the Research Innovation Key Project of Education Committee of Shanghai (No: 14ZZ137) and the Hujiang Foundation of China (B14004). 


\section{References}

[1] Iijima, S. (1991) Helical Microtubules of Graphitic Carbon. Nature, 354, 56-58.

http://www.nature.com/physics/looking-back/iijima/index.html http://dx.doi.org/10.1038/354056a0

[2] Nishimura, K., Jiang, N. and Hiraki, A. (2003) Growth and Characterization of Carbon Nanowalls. IEICE Transactions on Electronics, 86, 821-824. http://search.ieice.org/bin/summary.php?id=e86-c_5_821

[3] Zajec, B., Nemanic, V., Zumer, M., Bryan, E.N. and Nemanich, R.J. (2011) Ring-Shaped Field Emission Patterns from Carbon Nanotube Films. Carbon, 49, 3332-3339.

http://www.sciencedirect.com/science/article/pii/S0008622311002843

http://dx.doi.org/10.1016/j.carbon.2011.04.020

[4] Dionne, M., Coulombe, S. and Meunier, J.L. (2009) Energy Exchange during Electron Emission from Carbon Nanotubes: Considerations on Tip Cooling Effect and Destruction of the Emitter. Physical Review B, 80, 085429. http://journals.aps.org/prb/abstract/10.1103/PhysRevB.80.085429 http://dx.doi.org/10.1103/physrevb.80.085429

[5] Baik, C.W., Lee, J., Choi, J. H., Jung, I., Choi, H.R., Jin, Y.W. and Kim, J.M. (2010) Structural Degradation Mechanism of Multiwalled Carbon Nanotubes in Electrically Treated Field Emission. Applied Physics Letters, 96, 023105. http://dx.doi.org/10.1063/1.3291108

[6] Malesevic, A., Vitchev, R., Schouteden, K., Volodin, A., Zhang, L., van Tendeloo, G., Vanhulsel, A. and Haesendonck, C.V. (2008) Synthesis of Few-Layer Graphene via Microwave Plasma-Enhanced Chemical Vapour Deposition. Nanotechnology, 19, 305604. http://iopscience.iop.org/0957-4484/19/30/305604 http://dx.doi.org/10.1088/0957-4484/19/30/305604

[7] Takeuchi, W., Kondo, H., Obayashi, T., Hiramatsu, M. and Hori, M. (2011) Electron Field Emission Enhancement of Carbon Nanowalls by Plasma Surface Nitridation. Applied Physics Letters, 98, 123107. http://scitation.aip.org/content/aip/journal/apl/98/12/10.1063/1.3532114 http://dx.doi.org/10.1063/1.3532114

[8] Wang, X.P., Wang, L.J., Liu, X.F., Yang, C., Jing, L.W. and Pan, X.F. (2013) The Synthesis of Vertically Oriented Carbon Nanosheet-Carbon Nanotube Hybrid Films and Their Excellent Field Emission Properties. Carbon, 58, 170 174. http://www.sciencedirect.com/science/article/pii/S0008622313001863 http://dx.doi.org/10.1016/j.carbon.2013.02.045

[9] Shimoi, N., Estrada, A.L., Tanaka, Y. and Tohji, K. (2013) Properties of a Field Emission Lighting Plane Employing Highly Crystalline Single-Walled Carbon Nanotubes Fabricated by Simple Processes. Carbon, 65, 228-235. http://www.sciencedirect.com/science/article/pii/S000862231300780X

[10] Kaushik, V., Shukla, A.K. and Vankar, V.D. (2013) Improved Electron Field Emission from Metal Grafted Graphene Composites. Carbon, 62, 337-345. http://www.sciencedirect.com/science/article/pii/S0008622313005228

[11] Xiang, J., Lu, W., Hu, Y.J., Wu, Y., Yan, H. and Lieber C.M. (2006) Ge/Si Nanowire Heterostructures as HighPerformance Field-Effect Transistors. Nature, 441, 489-493. http://www.nature.com/nature/journal/v441/n7092/abs/nature04796.html http://dx.doi.org/10.1016/j.carbon.2013.06.016

[12] Jin, S., Whang, D., McAlpine, M.C., Friedman, R.S., Wu, Y. and Lieber, C.M. (2004) Scalable Interconnection and Integration of Nanowire Devices without Registration. Nano Letters, 4, 915-919.

http://pubs.acs.org/doi/abs/10.1021/nl049659j http://dx.doi.org/10.1038/nature04796

[13] Wu, Y., Xiang, J., Yang, C., Lu, W. and Lieber C.M. (2004) Single-Crystal Metallic Nanowires and Metal/Semiconductor Nanowire Heterostructures. Nature, 430, 61-65. http://www.nature.com/nature/journal/v430/n6995/abs/nature02674.html http://dx.doi.org/10.1038/nature02674

[14] Shuvo, M.A.I., Tseng, T.L., Khan, Md. A.R., Karim, H., Morton, P., Delfin, D. and Lin, Y. (2013) Nanowire Modified Carbon Fibers for Enhanced Electrical Energy Storage. Journal of Applied Physics, 114, 104306. http://scitation.aip.org/content/aip/journal/jap/114/10/10.1063/1.4820942

[15] Ghalamestani, S.G., Ek, M., Ganjipour, B., Thelander, C., Johansson, J., Caroff, P. and Dick, K.A. (2012) Demonstration of Defect-Free and Composition Tunable $\mathrm{Ga}_{\mathrm{x}} \mathrm{In}_{1-\mathrm{x}} \mathrm{Sb}$ Nanowires. Nano Letters, 12, 4914-4919. http://pubs.acs.org/doi/abs/10.1021/nl302497r http://dx.doi.org/10.1021/nl302497r

[16] Svensson, J., Anttu, N., Vainorius, N., Borg, B.M. and Wernersson, L.E. (2013) Diameter-Dependent Photocurrent in InAsSb Nanowire Infrared Photodetectors. Nano Letters, 13, 1380-1385. 
http://pubs.acs.org/doi/abs/10.1021/nl303751d http://dx.doi.org/10.1021/nl303751d

[17] Patolsky, F., Zheng, G. and Lieber, C.M. (2006) Fabrication of Silicon Nanowire Devices for Ultrasensitive, LabelFree, Real-Time Detection of Biological and Chemical Species. Nature Protocols, 1, 1711-1724.

http://www.nature.com/nprot/journal/v1/n4/abs/nprot.2006.227.html http://dx.doi.org/10.1038/nprot.2006.227

[18] She, J.C., Deng, S.Z., Xu, N.S., Yao, R.H. and Chen, J. (2006) Fabrication of Vertically Aligned Si Nanowires and Their Application in a Gated Field Emission Device. Applied Physics Letters, 88, 013112. http://scitation.aip.org/content/aip/journal/apl/88/1/10.1063/1.2162692 http://dx.doi.org/10.1063/1.2162692

[19] Li, C., Zhang, Y., Mann, M., Hiralal, P., Unalan, H.E., Lei, W. and Wang, B.P. (2010) Stable, Self-Ballasting Field Emission from Zinc Oxide Nanowires Grown on an Array of Vertically Aligned Carbon Nanofibers. Applied Physics Letters, 96, 143114. http://scitation.aip.org/content/aip/journal/apl/96/14/10.1063/1.3380597 http://dx.doi.org/10.1063/1.3380597

[20] Huo, K.F., Zhang, X.M., Hu, L.S., Sun, X.J., Fu, J.J. and Chu, P.K. (2008) One-Step Growth and Field Emission Properties of Quasialigned $\mathrm{TiO}_{2}$ Nanowire/Carbon Nanocone Core-Shell Nanostructure Arrays on Ti Substrates. Applied Physics Letters, 93, 013105. http://adsabs.harvard.edu/abs/2008ApPhL..93a3105H http://dx.doi.org/10.1063/1.2955519

[21] Fang, X.S., Bando, Y., Ye, C.H., Shen, G.Z., Gautam, U.K., Tang, C.C. and Golberg, D. (2007) Si Nanowire Semisphere-Like Ensembles as Field Emitters. Chemical Communications, No. 40, 4093-4095. http://pubs.rsc.org/en/content/articlelanding/2007/cc/b701113j/unauth http://dx.doi.org/10.1039/b701113j

[22] Zeng, B.Q., Xiong, G.Y., Chen, S., Wang, W.Z., Wang, D.Z. and Rena, Z.F. (2007) Field Emission of Silicon Nanowires Grown on Carbon Cloth. Applied Physics Letters, 90, 033112. http://scitation.aip.org/content/aip/journal/apl/90/3/10.1063/1.2428543 http://dx.doi.org/10.1063/1.2428543

[23] Cao, X.H., He, Q.Y., Shi, W.H., Li, B., Zeng, Z.Y., Shi, Y.M., Yan, Q.Y. and Zhang, H. (2011) Graphene Oxide as a Carbon Source for Controlled Growth of Carbon Nanowires. Small, 7, 1199-1202. http://onlinelibrary.wiley.com/doi/10.1002/smll.201100071/full http://dx.doi.org/10.1002/smll.201100071

[24] Steinhart, M., Liang, C.D., Lynn, G.W., Gosele, U. and Dai, S. (2007) Direct Synthesis of Mesoporous Carbon Microwires and Nanowires. Chemistry of Materials, 19, 2383-2385. http://pubs.acs.org/doi/abs/10.1021/cm070455o http://dx.doi.org/10.1021/cm0704550

[25] Jeong, N., Jang, C.Y., Kim, H., Jeong, H., Yeo, J.G., Park, Y.C. and Hwang, K.S. (2013) Microscopic and Spectroscopic Analyses of Pt-Decorated Carbon Nanowires Formed on Carbon Fiber Paper. Microscopy and Microanalysis, 19, 198-201. http://journals.cambridge.org/action/displayAbstract?fromPage=online\&aid=8965335\&fileId=S1431

[26] Kumar, A., Avasthi, D.K., Tripathi, A., Filip, L.D., Carey, J.D. and Pivin, J.C. (2007) Formation and Characterization of Carbon Nanowires. Journal of Applied Physics, 102, 044305. http://scitation.aip.org/content/aip/journal/jap/102/4/10.1063/1.2767227 http://dx.doi.org/10.1063/1.2767227

[27] Ni, Z.C., Li, Q.T., Zhu, D.Z. and Gong, J.L. (2006) Fabrication of Carbon Nanowire Networks by Si Ion Beam Irradiation. Applied Physics Letters, 89, 053107. http://scitation.aip.org/content/aip/journal/apl/89/5/10.1063/1.2245372 http://dx.doi.org/10.1063/1.2245372

[28] Han, Z.J., Yick, S., Levchenko, I., Tam, E., Yajadda, M.M.A., Kumar, S., Martin, P.J., Furman, S. and Ostrikov, K. (2011) Controlled Synthesis of a Large Fraction of Metallic Single-Walled Carbon Nanotube and Semiconducting Carbon Nanowire Networks. Nanoscale, 3, 3214-3220. http://pubs.rsc.org/en/content/articlehtml/2011/nr/c1nr10327j http://dx.doi.org/10.1039/c1nr10327j

[29] Takagi, D., Kobayashi, Y., Hibino, H., Suzuki, S. and Homma, Y. (2008) Mechanism of Gold-Catalyzed Carbon Material Growth. Nano Letters, 3, 832-835. http://pubs.acs.org/doi/abs/10.1021/nl0728930 http://dx.doi.org/10.1021/nl0728930

[30] Nemanich, R.J. and Solin, S.A. (1979) First- and Second-Order Raman Scattering from Finite-Size Crystals of Graphite. Physical Review B, 20,392-401. http://journals.aps.org/prb/abstract/10.1103/PhysRevB.20.392 http://dx.doi.org/10.1103/physrevb.20.392

[31] Ni, Z.H., Fan, H.M., Feng, Y.P., Shen, Z.X., Yang, B.J. and Wu, Y.H. (2006) Raman Spectroscopic Investigation of Carbon Nanowalls. Journal of Chemical Physics, 124, 204703-5. http://scitation.aip.org/content/aip/journal/jcp/124/20/10.1063/1.2200353 
http://dx.doi.org/10.1063/1.2200353

[32] Ferrari, A.C. and Robertson, J. (2000) Interpretation of Raman Spectra of Disordered and Amorphous Carbon. Physical Review B, 61, 14095-14107. http://journals.aps.org/prb/abstract/10.1103/PhysRevB.61.14095 http://dx.doi.org/10.1103/physrevb.61.14095

[33] Dillon, R.O., Woollam, John. A. and Katkanant, V. (1984) Use of Raman Scattering to Investigate Disorder and Crystallite Formation in As-Deposited and Annealed Carbon Films. Physical Review B, 29, 3482-3489.

http://journals.aps.org/prb/abstract/10.1103/PhysRevB.29.3482 http://dx.doi.org/10.1016/0008-6223(84)90365-8

[34] Jorio, A., Saito, R., Hafner, J. H., Lieber, C.M., Hunter, M., McClure, T., Dresselhaus, G. and Dresselhaus, M.S. (2001) Structural $(n, m)$ Determination of Isolated Single-Wall Carbon Nanotubes by Resonant Raman Scattering. Physical Review Letters, 86, 1118-1121. http://journals.aps.org/prl/abstract/10.1103/PhysRevLett.86.1118 http://dx.doi.org/10.1103/PhysRevLett.86.1118

[35] Rao, A.M., Richter, E., Bandow, S., Chase, B., Eklund, P.C., Williams, K.A., Fang, S., Subbaswamy, K.R., Menon, M., Thess, A., Smalley, R.E., Dresselhaus G. and Dresselhaus, M.S. (1997) Diameter-Selective Raman Scattering from Vibrational Modes in Carbon Nanotubes. Science, 275, 187-191.

http://www.sciencemag.org/content/275/5297/187.short http://dx.doi.org/10.1126/science.275.5297.187 